\title{
La lucha por la urbanización y el rol de la judicialización en una villa de la Ciudad de Buenos Aires
}

\author{
The struggle for urbanization and the role of judiciary in a shanty town in the City of Buenos \\ Aires
}

María Florencia Rodríguez •

\section{Resumen}

En este artículo se aborda el proceso de judicialización de una villa localizada en un área privilegiada de la Ciudad de Buenos Aires actualmente en instancia de reurbanización. Se trata de la "Rodrigo Bueno", como ha sido llamada por sus habitantes, una de las cuatro villas atravesada por la política de Integración Social y Urbana que lleva adelante el Gobierno de la Ciudad.

Si bien el GCBA viene impulsando la reurbanización de este barrio a la luz de grandes transformaciones urbanas y dinámicas de valorización de la zona, el reclamo de los habitantes por la radicación y la permanencia en el lugar antecede a tal intervención a través de estrategias diversas como ha sido la judicialización.

En estas páginas me propongo analizar el papel de la judicialización de la Villa Rodrigo Bueno, durante el período 2005-2015, tomando en cuenta el entramado actoral desplegado en el "campo jurídico" de una situación declarada conflictiva, y sus efectos sociales y territoriales en un área disputada de la ciudad.

En este marco y desde una perspectiva de las ciencias sociales, entendemos a la judicialización como una arena más en la que se cristaliza un conflicto social preexistente -en este caso referido a la inscripción territorial y la permanencia de un sector social (popular) en el espacio urbano- en el cual diversos actores despliegan posicionamientos (argumentales y de construcción de sentido del problema) diferentes, según las instancias y los contextos en los que se encuentran.

Palabras claves: Urbanización, Judicialización, Villa Rodrigo Bueno.

\begin{abstract}
This article discusses the process of judiciary of a shanty town located in a privileged area of the City of Buenos Aires currently in instance of redevelopment. It is the "Rodrigo Bueno", as it has been called by its inhabitants, one of the four shantu town crossed by the policy of Social and Urban Integration carried out by the Government of the City.

Although the current GCBA has been promoting the redevelopment of this neighborhood in light of major urban transformations and dynamics of valorization of the area, the inhabitants' demand for the establishment and permanence in the place precede such intervention through strategies diverse as the judiciary has been.

In these pages, I propose to analyze the role of judiciary in Rodrigo Bueno, during the period 2005-2015, taking into account the network of actors deployed in the "legal field" of a situation declared conflictive, and its effects social and territorial in a disputed area of the city.
\end{abstract}

\footnotetext{
- Socióloga. Dra. en Ciencias Sociales. Investigadora asistente del CONICET con sede en el Instituto de Investigaciones Gino Germani, Facultad de Ciencias Sociales. Universidad de Buenos Aires. mafloro@gmail.com
}

Recibido: 17/4/2020. Publicable con correcciones: 17/6/2020. 
In this framework and from a perspective of the social sciences, we understand judiciary as one more arena in which a pre-existing social conflict is crystallized -in this case referring to territorial registration and the permanence of a (popular) social sector in the urban space- in which different actors deploy different positions (arguments and construction of the problem), according to the instances and contexts in which they are found.

Keywords: Urbanization, Judiciary, Shanty town Rodrigo Bueno. 


\section{La lucha por la urbanización y el rol de la judicialización en una villa de la Ciudad de Buenos Aires}

María Florencia Rodríguez

\section{Introducción}

En este artículo se aborda el proceso de judicialización de una villa localizada en un área privilegiada de la Ciudad de Buenos Aires actualmente en instancia de reurbanización. Se trata de la "Rodrigo Bueno", como ha sido llamada por sus habitantes, una de las cuatro villas atravesada por la política de Integración Social y Urbana que lleva adelante el Gobierno de la Ciudad.

La idea que sostenemos es que si bien el GCBA viene impulsando la reurbanización de este barrio a la luz de grandes transformaciones urbanas y dinámicas de valorización de la zona, el reclamo de los habitantes por la radicación y permanencia en el lugar antecede a tal intervención, a través de estrategias diversas como ha sido la judicialización. Señalamos que estas demandas a través de papeles y legajos fueron habilitantes del actual escenario de intervención que despliega el Jefe de Gobierno, Horacio Rodríguez Larreta ${ }^{1}$, bajo la consigna de la "urbanización".

El presente artículo invita a pensar, desde la perspectiva de las ciencias sociales, a la judicialización como una arena más en la que se cristaliza un conflicto social preexistente. Un conflicto que remite a los usos y apropiación del suelo, evidenciado a partir de las tensiones y diputas en torno a la inscripción territorial y permanencia de un sector (popular) en un área central de la ciudad. La judicialización es una de esas arenas en el que se manifiesta el conflicto urbano y en la cual distintos actores intervinientes despliegan posicionamientos (argumentales y de construcción de sentido del problema) diferentes, según las instancias y los contextos en los que se encuentren.

En este sentido, el objetivo del artículo es analizar el proceso de judicialización impulsado por los habitantes de la villa Rodrigo Bueno en defensa al derecho a la vivienda y a la ciudad, durante el período 2005-2015, y el entramado actoral desplegado en el "campo jurídico", de una situación declarada conflictiva. Para ello recupero los aportes de Merlinsky (2015), Melé (2003), Azuela y Cosacov (2013) acerca de los efectos sociales de la juridificación y la productividad social de los conflictos urbanos. Asimismo el trabajo se nutre de una estrategia

\footnotetext{
${ }^{1}$ Horacio Rodríguez Larreta es actualmente Jefe de Gobierno de la Ciudad de Buenos Aires. Su primer mandato comenzó en diciembre de 2015 hasta diciembre de 2019, donde fue reelecto, ejerciendo al presente su segundo mandato hasta diciembre de 2023.
} 
metodológica cualitativa a partir de la utilización de fuentes secundarias de información (artículos periodísticos, leyes, decretos, expedientes y resoluciones jurídicas); y fuentes primarias a través de mis observaciones de campo, realizadas durante el período de análisis, en el barrio (concretamente en reuniones de vecinos con funcionarios del poder ejecutivo y judicial y durante el proceso eleccionario) y en la Legislatura de la Ciudad (donde diputados discutieron los proyectos de urbanización de Rodrigo Bueno y de las tierras aledañas bajo propiedad de IRSA).

\section{Conflictos y judicialización}

En este apartado pondremos énfasis en los conflictos territoriales entendiendo por tales a los conflictos sociales en los que se disputa el control por el territorio (Melé, 2003). Merlinsky, en sus estudios sobre conflictos, señala la importancia de comprender "cómo se definen colectivamente formas de justificación, se construyen significados sociales y se transforman los registros de legitimidad en torno a lo que debe hacerse en relación a los problemas ambientales y urbanos" (2015:7). Siguiendo a la autora, no se trata de pensar en términos de vencedores y vencidos, más bien entender los efectos, "la productividad del conflicto" en tanto conjunto de transformaciones a mediano plazo que éstos generan en las relaciones sociales y en la vida social (Merlinsky, 2015:7).

Estos conflictos pueden manifestarse en distintas arenas, una de ellas es la jurídica y judicial. Azuela hace referencia a cómo ciertas cuestiones de la realidad social son problematizadas en el campo del derecho. Entiende a la juridificación "como un proceso social mediante el cual una serie de expectativas normativas se convierten en enunciados jurídicos y son incorporados al universo simbólico en el que tiene sentido la práctica social"' (Azuela, 2006:485). Azuela y Cosacov (2013) también señalan la importancia que asume la productividad social del conflicto, es decir, cómo es construida, cómo se instala, una situación considerada problemática, en el campo judicial, para su posible resolución. Esto implica, siguiendo a los autores, que el paso del "conflicto"/"problema" por el recurso judicial requiere necesariamente de un despliegue de repertorios de argumentaciones por parte de los actores involucrados en un intento de interpelar a otros y colocar como común aquello que se está afectando (Azuela y Cosacov, 2013). Una construcción argumentativa que no es unívoca ni homogénea, y por tanto no está exenta de tensiones y disputas en torno al modo en que ese "problema" es percibido por cada actor.

Desde un abordaje sociológico, y siguiendo a Azuela, no se trata de considerar las normas en sí mismas más bien de interpretar el sentido que ellas tienen para los actores sociales 
intervinientes (Azuela, 2006). Este autor evidencia la creencia pública acerca del valor del estado de derecho y la idea de que la "vigencia efectiva de un orden jurídico crea condiciones virtuosas para la sociedad" (Azuela, 2014:12). Existe una expectativa creciente en los últimos años de parte de los involucrados sobre lo que los jueces pueden aportar en torno al cumplimiento de los derechos sociales y de tercera generación, como la vivienda y el medioambiente. En este sentido, se alude a la confianza y valoración socialmente construida acerca de la "eficiencia" del derecho y los efectos sociales que puede generar la juridificación. En ocasiones, determinados grupos recurren a la justicia para hacer valer sus intereses y demandas. La judicialización remite así a la intervención del poder judicial en la resolución de una problemática ligada a la vulneración de derechos hacia un sector de la población (Ramos y Vitale, 2011). Estas acciones judiciales suelen ser impulsadas por personas afectadas de manera colectiva, en muchos casos acompañados por asociaciones civiles y de derechos humanos. Ejemplos de esto es el accionar de la Asociación Civil por la Igualdad y la Justicia (ACIJ) que ha iniciado causas judiciales en torno al acceso a servicios básicos en las villas (agua, tendido eléctrico, mejores condiciones sanitarias). También el proceder de la Asamblea Permanente por los Derechos Humanos (APDH) que trabajó activamente con los habitantes de Rodrigo Bueno en la elaboración de un amparo judicial ante la operatoria de desalojo del GCBA en el año 2005.

A continuación veremos cómo estas dinámicas se hicieron presentes, cada vez más, en los barrios populares y villas de la Ciudad de Buenos Aires, durante las dos últimas décadas.

\section{La judicialización de villas de la Ciudad}

El proceso de judicialización de villas a escala local cobró fuerza a partir de una serie de cambios institucionales y normativos, a nivel nacional y de la Ciudad, que hicieron de la vía judicial una estrategia válida de reclamo para sectores socialmente postergados.

Entre las modificaciones normativas cabe señalar la reforma constitucional de 1994 que posibilitó la incorporación de nuevos derechos sociales consagrados en los tratados internacionales de derechos humanos con jerarquía constitucional. ${ }^{2}$ A la vez se incluyó una cláusula de igualdad sustantiva que favoreció la acción positiva de protección de grupos subordinados incidiendo en las obligaciones estatales, como también nuevos mecanismos procesales que facilitaron la acción judicial colectiva (Abramovich, 2009). Esto permitió que

\footnotetext{
${ }^{2}$ Entre ellos, el derecho a la vivienda, salud y educación.
} 
ciertos asuntos tradicionalmente resueltos por el sistema político (ejecutivo) empezaran a ser tratados más concurrentemente por los jueces.

Las modificaciones normativas y jurídicas también generaron impactos a nivel local- Ciudad. Con la reforma de la Constitución Nacional, Buenos Aires adquirió status de ciudad autónoma, esto significó un régimen de gobierno propio $^{3}$ y la sanción, en 1996, de su Constitución. ${ }^{4}$ Asimismo se creó una nueva institucionalidad, el fuero Contencioso Administrativo y Tributario de la Ciudad ${ }^{5}$, que posibilitó la generación de casos judiciales en defensa de los Derechos, Económicos Sociales y Culturales (DESC). Este fuero se convirtió en un espacio válido para debatir acciones de amparo en situaciones donde, por acción u omisión, las dependencias del Poder Ejecutivo hayan vulnerado el acceso a un derecho social, especialmente hacia poblaciones de bajos recursos (López Oliva, 2009).

La incorporación de pactos y protocolos supranacionales de derechos humanos a la Constitución Nacional, el carácter colectivo y constitucional de las demandas, y la intervención de actores gubernamentales (generación joven de jueces y magistrados por concurso) y no gubernamentales (Defensoría del Pueblo y asociaciones civiles en defensa de los derechos humanos) constituyeron un escenario propicio para el despliegue de procesos de judicialización (Maurino y Nino, 2009). En sintonía, Azuela (2014) sostiene que una de las tendencias del nuevo papel de los jueces frente a los conflictos urbanos es recurrir cada vez más a los derechos fundamentales como soportes de sus decisiones, y no solo a la legislación nacional. A su vez nuevos actores aparecen en la escena judicial, mediante la creación de órganos especializados -con cierta autonomía- como procuradores, defensores del pueblo, ministerio público, o en otras circunstancias con la injerencia de las propias organizaciones sociales (Azuela, 2014).

En la Ciudad de Buenos Aires los reclamos judiciales frente al ejecutivo de la Ciudad han sido patrocinados por la APDH, el Ministerio Público de la Defensa y el Ministerio Público $\operatorname{Tutelar}^{6}$ sobre temas de acceso a la alimentación, provisión de servicios básicos, y otras

\footnotetext{
${ }^{3}$ Esto significaba que los intendentes de la Capital Federal ya no eran designados de manera directa por el Presidente de la Nación sino que serían los propios habitantes de la ciudad quienes elegirían a su Jefe de Gobierno a través del voto popular.

${ }^{4}$ La Constitución de la Ciudad Autónoma de Buenos reconoce explícitamente los Derechos Económicos, Sociales y Culturales (DESC) y con ello el establecimiento de garantías ciudadanas, a la vez que enfatiza la responsabilidad del Estado local para respetar, proteger, promover y dar cumplimiento a la efectivización de los derechos.

${ }^{5}$ El mismo fue pensado como instancia para tratar los reclamos de derecho público y privado en los que el Gobierno de la Ciudad de Buenos Aires estaba involucrado como parte o demandado (Ver López Oliva, 2009).

${ }^{6}$ López Oliva (2009) plantea como un aspecto distintivo en estos órganos pertenecientes al Poder Judicial de la Ciudad, la presencia de magistrados (que en el ejercicio de sus funciones asignadas por la normativa) asumieron la defensa de los derechos sociales como un objetivo central.
} 
cuestiones de índole habitacional (por ejemplo desalojos, contaminación, salubridad, hacinamiento).

A principios de la década del 2000, estas prácticas de litigio comenzaron a tener por protagonistas -con mayor fuerza- a los habitantes de varias villas de la ciudad, a la luz de los cambios normativos e institucionales anteriormente mencionados. Este "activismo judicial", al cual alude Delamata (2016), implicó el despliegue de estrategias de articulación y acompañamiento a los habitantes de las villas de parte de organizaciones civiles de derechos humanos, y organismos públicos no estatales. A través del litigo se puso de manifiesto el reclamo por la falta de acceso a servicios básicos, equipamientos e infraestructura urbana pero también la necesidad de impulsar mecanismos formales de representatividad política en estos barrios, mediante los procesos de elección de delegados. Todos los reclamos fueron expresados bajo la forma de demandas de derechos, tanto habitacionales como políticos, en la lucha por la ciudadanía urbana de estos habitantes (Delamata, Sehtman y Ricciardi, 2014; Delamata, 2016). Siguiendo a los autores, estas judicializaciones han dado cuenta de un proceso de desplazamiento de la conflictividad barrial a la esfera judicial reconfigurando la relación entre las villas y el Estado.

\section{Rodrigo Bueno. La judicialización a partir del desalojo}

La villa Rodrigo Bueno está ubicada sobre la Avenida España al 1800, dentro de la Comuna 1 de la Ciudad de Buenos Aires, correspondiente a la zona de la Costanera Sur. Linda actualmente con la Reserva Ecológica y con la ex Ciudad Deportiva de Boca Juniors, a pocos metros del barrio de Puerto Madero.

Mapa 1. Rodrigo Bueno en Comuna 1 


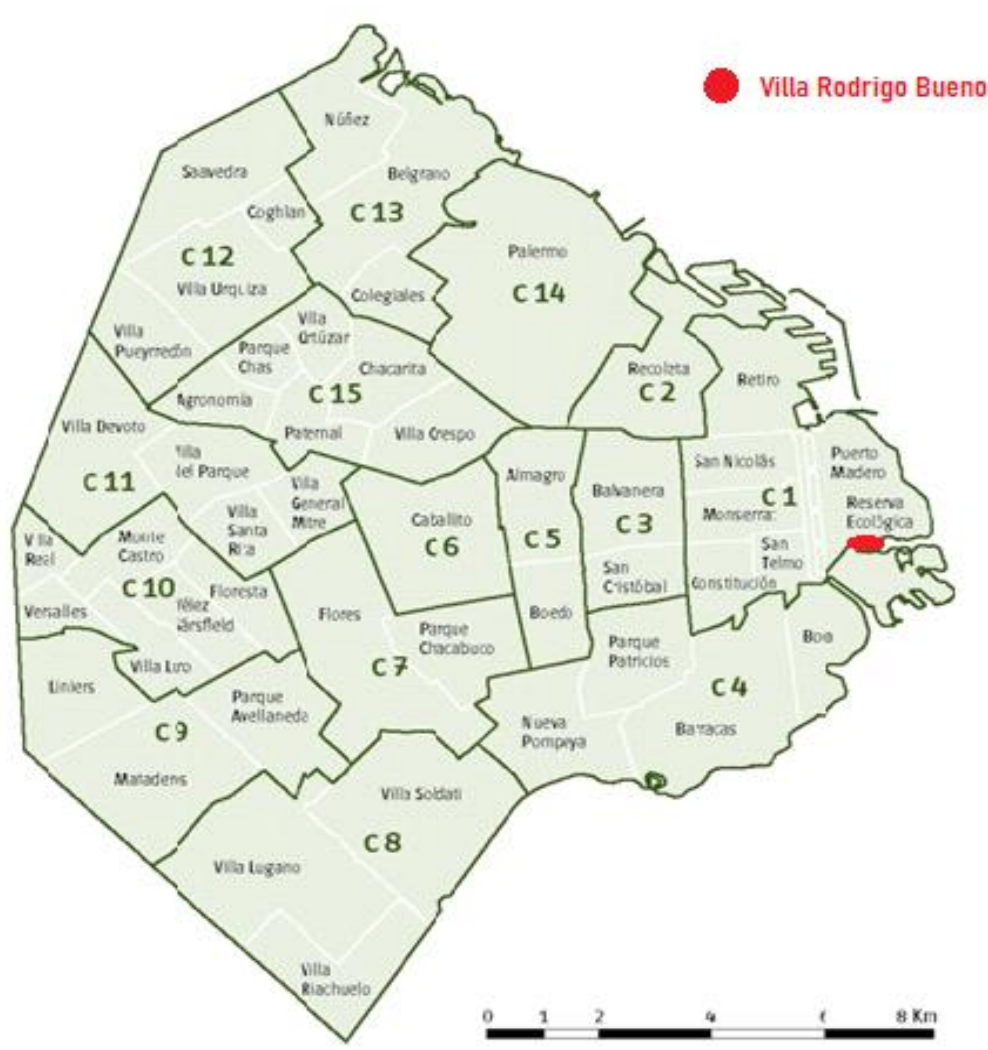

Fuente: elaboración propia en base a DGEyC, GCABA.

\section{Mapa 2. Localización Rodrigo Bueno}

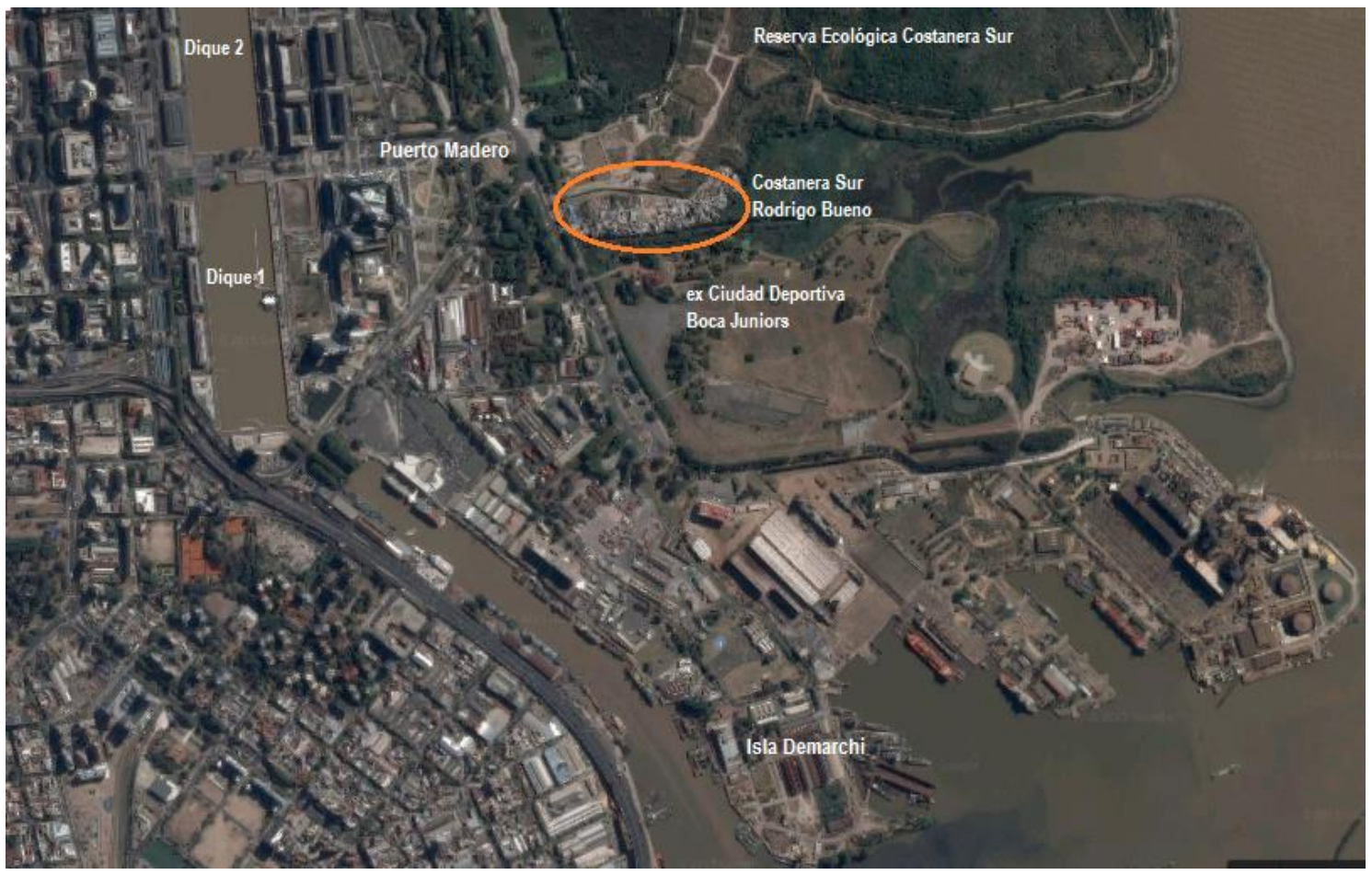

Fuente: elaboración propia en base al Google Maps. 
Los primeros habitantes se asentaron en esos predios depreciados de propiedad pública a comienzos de los años 80 . Aunque era una zona relegada poseía una localización privilegiada de excelente accesibilidad, próxima al centro administrativo y financiero de la ciudad. A partir de la década de 1990, estas tierras pasaron a adquirir una nueva funcionalidad vinculada a los intereses del capital financiero y a las dinámicas de la economía global convirtiéndose en un área de oportunidad para el desarrollo de inversiones urbanas (Cuenya, 2011). La compañía “Inversiones y Representaciones Sociedad Anónima” (IRSA)7 compró en 1997 los predios de la ex Ciudad Deportiva de Boca Juniors ubicados en la zona de la Costanera Sur. El objetivo era impulsar la construcción de un complejo habitacional de alta gama que incluyera comercios, hoteles, espacios verdes y recreación náutica, conocido como "Solares Santa María” o "Santa María del Plata". A lo largo de los años, IRSA insistió en la presentación de este mega-emprendimiento urbano en la Legislatura de la Ciudad para su aprobación. ${ }^{8}$ El interés por el despliegue de este emprendimiento en la zona abrió un conflicto acerca de los usos del suelo urbano y la existencia de la Villa Rodrigo Bueno en el lugar.

A partir del 2004, el GCBA comenzó a intervenir más en el área en cuestión y a tomar contacto con los vecinos del barrio. Frente a la preocupación y el riesgo latente a una expulsión, los delegados comenzaron a desempeñar un rol activo dentro y fuera de la villa. En este marco, asistieron a las mesas de diálogo que se realizaron en la Legislatura y en las oficinas de Desarrollo Social, hablaron con las autoridades estatales, incluso con quien fuera el Vicejefe de Gobierno Jorge Telerman, para intentar conciliar una alternativa que fuera acorde a las necesidades de las familias. En estas reuniones, donde ya se anunciaba un destino distinto para esos predios, los referentes manifestaron la necesidad de atender la urgencia y garantizar la provisión de los servicios básicos. La estrategia de los vecinos era que, a través de estas exigencias mínimas de obtención de servicios, la villa se consolidara para luego negociar desde otro lugar la permanencia en el lugar. El Vicejefe de Gobierno prometió agua potable, luz, cloacas e incluso cajas de alimentos hasta tanto se definieran las pautas de liberación de los predios.

Así mientras para algunos referentes el mejoramiento de las condiciones de vida era pensado como antesala para reforzar el derecho sobre esas tierras y consolidar la lucha por la

\footnotetext{
${ }^{7}$ IRSA es una de las empresas inversoras en bienes raíces más importantes de la Argentina centrada en la adquisición, desarrollo y puesta en valor de terrenos orientados a emprendimientos, tales como edificios de oficinas, residenciales, hoteles, shoppings y centros comerciales, entre otros.

${ }^{8}$ Este proyecto inmobiliario requiere para su realización de la modificación del Código de Planeamiento Urbano motivo por el cual ha sido presentado y debatido en la Legislatura de la Ciudad. En las siguientes páginas veremos que si bien el Bloque del PRO apoyó este desarrollo urbano, han sido varias las críticas de diputados de partidos opositores en rechazo al proyecto.
} 
radicación; para el ejecutivo del GCBA la intervención sirvió para entablar contacto con los habitantes y de ese modo lograr cierta confianza al momento de negociar la salida del lugar. Las mejoras en el barrio avanzaron del mismo modo que la decisión de desocupar las tierras. Finalmente, en el 2005 el GCBA ${ }^{9}$ procedió a efectuar la operatoria de expulsión de los habitantes de Rodrigo Bueno. Esta intervención se desarrolló en el marco del Programa de Recuperación de Terrenos de la Reserva Ecológica ${ }^{10}$ con el argumento de que debían recuperarse esas tierras para la Reserva. ${ }^{11}$ A través de reuniones y comunicados, el GCBA brindó a las familias la posibilidad de optar por única vez entre un subsidio habitacional ${ }^{12} \mathrm{o}$ crédito hipotecario dentro del marco de la ley $341^{13}$. La idea de una desocupación de los predios de manera pacífica - tal como lo anunciaba el Gobierno de la Ciudad- cobraría otro giro, pues la imposibilidad "real" de los habitantes de acceder a un crédito ${ }^{14}$ y la negación de éstos a retirarse mediante un subsidio llevó al GCBA a efectuar acciones intimidatorias y violentas para lograr su objetivo. Con el fin de "desalentar" la permanencia de los habitantes, el GCBA procedió a la suspensión de los servicios en el barrio, junto a otras acciones más directas y no tan sutiles como amenazas verbales, acciones persecutorias, control policial y demolición de viviendas. ${ }^{15}$

Este "modus operandi" estatal fue la antesala al proceso de judicialización iniciado por los propios habitantes en defensa de sus viviendas. Mientras sucedía la operatoria, referentes y vecinos acudieron de manera conjunta a las abogadas de la APDH quienes ya trabajaban en el barrio. ${ }^{16}$ El conocimiento técnico y legal fue el recurso central que la APDH utilizó a los

\footnotetext{
${ }^{9}$ Por entonces el Jefe de Gobierno de la Ciudad era Aníbal Ibarra (2003-2006) y el Vicejefe de Gobierno Jorge Telerman a cargo también de la Secretaría de Desarrollo Social desde agosto de 2004 a noviembre de 2005.

${ }^{10}$ Decreto 1247/05 publicado en el B.O. N ${ }^{\circ} 2265$ el 31-08-2005.

${ }^{11}$ Recordemos que la Reserva Ecológica es considerada como tal en el año 1986 mediante la Ordenanza N ${ }^{\circ}$ 41.247/86, años posteriores al asentamiento de los primeros habitantes.

${ }^{12}$ Los subsidios ofrecidos por la Secretaría de Desarrollo Social rondaban entre los $\$ 7.000$ y \$20.000 pesos según la estructura familiar, cifra muy baja para acceder a la compra de un inmueble en la Ciudad y/o zonas aledañas.

${ }^{13}$ La Ley 341 fue sancionada por la legislatura porteña en diciembre de 2000. La misma tiene como propósito instrumentar políticas de acceso a vivienda para hogares de escasos recursos en situación habitacional crítica. Contempla tanto a destinatarios individuales como a personas incorporadas en procesos de organización colectiva, a través de cooperativas, mutuales o asociaciones civiles sin fines de lucro. En este proceso participaron fundamentalmente tres actores: organizaciones de base que desarrollan trabajos vinculados al hábitat en la ciudad de Buenos Aires, legisladores con experiencia en temas de vivienda y la Comisión Municipal de la Vivienda (hoy IVC), brazo ejecutor de la política habitacional del GCBA.

${ }^{14} \mathrm{Al}$ momento de la negociación la única alternativa concreta que ofrecía el Estado era la entrega de subsidios; sin posibilidad de acceso a los requisitos de los créditos como tampoco a una salida a través de cooperativas (Ver Rodríguez, 2015).

${ }^{15}$ Se puede acceder a trabajos previos para una mayor ampliación sobre el proceso de desalojo (Rodríguez, 2015; Rodríguez, 2012; von Lucken M. \& Rodríguez M. F., 2011; Rodríguez, 2009).

${ }^{16} \mathrm{La}$ APDH es una organización que se creó en 1975 con el objetivo de proteger, promover y defender derechos sociales y humanos. Varias abogadas de esta organización comenzaron a trabajar en el barrio Rodrigo Bueno, meses antes de producirse el desalojo, por pedido y demanda de los vecinos para brindar asesoramiento sobre temas referidos a los derechos sociales y culturales, así como al acceso a los medicamentos, a la educación, a la alimentación, y al trabajo. En el marco de la asesoría jurídica también trabajaron en torno al reconocimiento del
} 
fines de denunciar las irregularidades del desalojo y los impactos negativos hacia la población. La voluntad de los habitantes por permanecer en esas tierras permitió la confección del expediente. Los vecinos cooperaron con la firma del escrito y también reuniendo información -fotos, documentos, y sus propios testimonios - para dar cuenta de la existencia de la villa y su antigüedad en el lugar. De este modo, se buscó evidenciar la historia del barrio (su conformación y consolidación), el rol importante que desempeñaron los habitantes en la configuración de ese espacio (pues fueron ellos quienes rellenaron y ganaron tierra al río para construir sus viviendas) y la reproducción cotidiana de la vida de las familias (el uso de equipamientos e infraestructura -escuelas, centros de salud y fuentes de empleo- próximo a la zona). Estas cuestiones fueron volcadas en el expediente en defensa del barrio y en rechazo al violento proceso de desalojo desplegado por ejecutivo local. De este modo se dio curso al amparo judicial.

A partir del amparo, la Jueza Elena Liberatori, en lo Contencioso Administrativo y Tributario, dictó una medida cautelar donde ordenó la suspensión del desalojo, y exigió al GCBA un mejoramiento en las condiciones habitacionales (limpieza, higiene y provisión de servicios) como también apoyo psicológico a las mujeres y niños por lo sucedido. Finalmente, en marzo de 2011 la Jueza Liberatori dictó sentencia sobre esta causa. ${ }^{17}$

En su dictamen, la jueza Liberatori procedió a declarar la nulidad del Decreto 1247/05 (y su modificatorio $\mathrm{N}^{\circ}$ 2136/06) -referido al Programa de Recuperación de los Terrenos para la Reserva-. Argumentó que estas normativas eran contrarias a la Constitución de la Ciudad Autónoma de Buenos Aires en tanto promovían la expulsión de la población existente sin ofrecer una vivienda digna y hábitat adecuado. En sintonía con lo expuesto, la magistrada planteó la abstención del GCBA ${ }^{18}$ de efectuar desalojos o de llevar adelante cualquier medida segregatoria o expulsiva en relación a los habitantes de la villa.

Un aspecto importante del fallo es que se ordenó al GCBA efectuar acciones necesarias tendientes a la efectiva integración urbanística y social del barrio fijándole un plazo de 120 días para que presente un plan de urbanización. Éste fue sin duda el punto central de la sentencia, pues no sólo se planteó la inconstitucionalidad de la operatoria de desalojo sino también el reconocimiento del derecho a estos habitantes de permanecer en el lugar bajo

\footnotetext{
lugar como villa y la inclusión a procesos de urbanización y radicación. Estos vínculos previos fueron claves, pues contribuyeron a que la APDH desempeñara un rol importante junto a los vecinos en oposición a la operatoria de expulsión.

${ }^{17}$ Exp. 17699/0. Carátula "Zarate Villalba Juan Ramón y otros contra GCBA sobre amparo" (Art. 14 CCABA). Juzgado 1ra Inst. en lo Contencioso Administrativo y Tributario $\mathrm{N}^{\circ} 4$.

${ }^{18}$ En este momento, el Jefe de Gobierno de la Ciudad era Mauricio Macri (desde diciembre 2007 hasta diciembre 2011). Luego fue reelegido, ejerciendo su segundo mandato desde diciembre de 2011 hasta diciembre de 2015.
} 
criterios de radicación. En concordancia con esto, el Gobierno de la Ciudad debía dar participación efectiva a los residentes en relación al proyecto de reurbanización y decretar la incorporación del Barrio Rodrigo Bueno al Programa de Radicación e Integración de villas en el marco de la Ley $148 .{ }^{19}$ A su vez, en este marco, la judicialización habilitó "formalizar" la representación barrial. Desde el Juzgado N 2 Contencioso Administrativo y Tributario de la Ciudad, se dio impulso al proceso de intervención judicial con el objetivo de impulsar la elección formal de los/as delegados/as. ${ }^{20}$ Como venimos anticipando, la urbanización y el cumplimiento de los derechos habitacionales, iban de la mano del reconocimiento de los derechos políticos de estos habitantes.

La jueza tomó en consideración un conjunto de normativas jurídicas para dictar esta sentencia. Entre ellas, señaló el Artículo 31 de la Constitución de la Ciudad de Buenos Aires que promueve el derecho a una vivienda digna y a un hábitat adecuado, la Constitución Nacional, así como Declaraciones, Pactos y Convenciones de carácter internacional. ${ }^{21}$ Estas normativas internacionales expresan el derecho a la vivienda, a la seguridad de la persona, a la seguridad de hogar, a un nivel de vida adecuado. La relocalización es posible en tanto implique una mejora sustantiva en las condiciones de vida de la población -facilidad de acceso, asequibilidad, habitabilidad, adecuación del lugar, acceso a los servicios esenciales, salud, educación-, y no un agravamiento del estado actual de situación. ${ }^{22}$ Estos elementos fueron de

\footnotetext{
${ }^{19}$ La Ley 148 fue aprobada en el año 1998. Esta normativa plantea políticas de radicación definitiva mediante la conformación de una Comisión Coordinadora Participativa, integrada por representantes del Poder Ejecutivo, Legislativo y los habitantes de las villas. La ley habilita garantizar derechos políticos a los habitantes; esto es, que puedan elegir democráticamente a sus representantes barriales, y a partir de esa representación barrial promover proyectos de urbanización. Ambos derechos -los políticos y habitacionales- están íntimamente relacionados en el marco jurídico existente pero sin cumplimiento por décadas en muchas villas y asentamientos. Las irregularidades en el cumplimiento de la Ley 148 llevaron a vecinos de diferentes villas a denunciar ante la Comisión de Vivienda de la Legislatura de la Ciudad la falta de legitimidad de sus representantes y la caducidad de sus mandatos (Arqueros, Calderón, et. al 2013). Este procedimiento sirvió como puntapié y antesala para una serie de procesos de intervención judicial de los procesos eleccionarios en los barrios.

${ }^{20}$ La intervención comenzó en mayo de 2011 y estuvo a cargo del arquitecto Castellano y su equipo técnico, conformado por arquitectos, sociólogos/as y abogados. Las funciones del interventor judicial consistían en concretar el proceso eleccionario de conformidad con las instrucciones que impartirá el tribunal; operar como único intermediario entre el GCBA y los habitantes de la villa a fin de canalizar, encauzar y responder a la totalidad de los requerimientos de la población del asentamiento que se trate; y establecer como plazo de la intervención el que resulte de la finalización del procedimiento eleccionario que garantice los derechos de todos los interesados. Por primera vez, el 25 de marzo de 2012 los habitantes de Rodrigo Bueno votaron formalmente a sus representantes barriales. La Jueza Liberatori supervisó los comicios, asimismo participaron militantes de organizaciones sociales, investigadores sociales, diputados, y asesores de la Comisión de Vivienda de la Legislatura de la Ciudad.

${ }^{21}$ Entre los cuales cabe mencionar: la Declaración Universal de los Derechos Humanos, el Pacto Internacional de los Derechos Económicos, Sociales y Culturales, el Pacto Internacional de los Derechos Civiles y Políticos, el Pacto de San José de Costa Rica, la Convención sobre la Eliminación de la Discriminación Racial, la Convención sobre los Derechos del Niño.

${ }^{22}$ Las normativas internacionales plantean que los desalojos pueden llevarse a cabo de forma legal, únicamente en circunstancias excepcionales y de conformidad con las disposiciones del derecho internacional relativo a los derechos humanos y del derecho comunitario. Por contrapartida los desalojos forzosos intensifican la desigualdad, la segregación y la creación de guetos afectando invariablemente a los sectores más vulnerados (Ver Rodríguez, 2019).
} 
importancia en la resolución de la jueza en oposición a la operatoria de expulsión del GCBA y a favor de la urbanización del barrio.

Un aspecto relevante es que la magistrada no sólo se valió del corpus normativo y jurídico para dictar sentencia, también fueron incorporados a la causa informes técnicos e investigaciones de profesionales, académicos e investigadores del CONICET que sirvieron como sustento y argumento en el fallo. ${ }^{23}$ La presencia y colaboración de actores diversos permitió dar cuenta del perfil y perspectiva de la magistrada, pues si bien esto transcurrió dentro de los mecanismos y circuitos del campo judicial, la incorporación de material provisto por distintas disciplinas ligado a la salud, la arquitectura, y lo social, evidenció un esfuerzo por dar tratamiento a la problemática de la villa desde una perspectiva más compleja e integral. Las contribuciones e informes de antropólogas, sociólogas, arquitectos y profesionales de la salud de la UBA sirvieron a la Jueza para comprender el largo proceso histórico de conformación y consolidación del barrio en clave social, ambiental y física (construcción y topografía). Del mismo modo, la participación de otros actores de organismos públicos y asociaciones civiles como la Legislatura de la Ciudad ${ }^{24}$, la Defensoría del Pueblo ${ }^{25}$ y la $\mathrm{APDH}^{26}$.

En este marco, la sentencia tuvo efectos, y uno de ellos fue la aparición y participación de nuevos actores que no pertenecían al ámbito judicial. Desde la lógica del conocimiento, estos actores -con su expertise técnica, científica e ideológica-, introdujeron perspectivas y pusieron en circulación diferentes saberes a disposición de quienes toman decisiones en el proceso de

\footnotetext{
${ }^{23}$ Parte de mis producciones académicas fueron tomadas en cuenta en la causa como fuente de información. Esto fue muy relevante para mí, en el rol de Socióloga, pues implicó la posibilidad de poder pensar (más cercanamente) en la articulación entre la producción de conocimiento y los impactos concretos y su alcance práctico en cuanto a las necesidades reales de una población, en este caso, referida a la situación habitacional de los vecinos de Rodrigo Bueno. Es lo que Aranda anuncia como "porosidad de intercambios" al plantear que la intervención institucional del apartado judicial y las controversias socio-técnicas suponen la constitución y continuidad de colaboración de los afectados por el conflicto con portadores de saberes, profesionales o técnicos provenientes de áreas diversas (Alimonda, 2013). Cabe señalar que el saber científico y/o "expertise" en ciertos temas es utilizado como instrumento de argumentación para cada uno de los grupos que participan de la contienda, generando controversias. Veremos en las páginas que siguen que el GCBA también contará con abogados y especialistas del derecho quienes a través de sus interpretaciones y lecturas de las leyes buscarán justificar su oposición a la decisión de la jueza.

${ }^{24}$ En sintonía con el proceder del Asesor Titular (del Poder Judicial de la Ciudad), el presidente de la Comisión de la Vivienda de la Legislatura denunció la presencia de plomo en sangre y brindó toda su colaboración a los habitantes de Rodrigo Bueno en torno a propiciar el mejoramiento de las condiciones de habitabilidad y permanencia en el lugar.

${ }^{25}$ En varias oportunidades la Defensoría del Pueblo de la Ciudad puso en conocimiento a las autoridades estatales del gobierno local sobre los impactos ambientales del cementerio de autos a la población Rodrigo Bueno. A través de la Resolución N 0720/09, la Defensoría resolvió recomendar al Ministerio de Ambiente y Espacio Público del GCBA desactivar la playa policial emplazada en terrenos de la Reserva Ecológica; y realizar, a través de los organismos técnicos competentes, estudios de evaluación de contaminación y, en caso de corresponder, de remediación del suelo de la fracción de terreno.

${ }^{26}$ Médicos perteneciente a la Comisión de Salud de la APDH han acompañado activamente a los habitantes de Rodrigo Bueno en los temas de salud y contaminación ambiental que mujeres, jóvenes y niños, fundamentalmente, padecen.
} 
producción de la ciudad y en la representación de la misma (Pírez, 1995; Merlinsky, 2015). La sentencia de la jueza contó con una multiplicidad de perspectivas, investigaciones e informes que sirvieron de sustento en esta instancia procedimental. El dictamen dejó en evidencia dos temas: la factibilidad técnica de la urbanización de Rodrigo Bueno reconociendo el derecho a los habitantes a un mejoramiento de las condiciones de habitabilidad en el lugar-; y la responsabilidad del GCBA de garantizar el proceso a través de un plan de integración urbanística y social del barrio.

\section{El revés del Gobierno de la Ciudad}

El Gobierno de la Ciudad tuvo una reacción adversa frente al dictamen judicial de brindar soluciones habitacionales concretas a los habitantes de Rodrigo Bueno. Rodríguez Larreta, quien fuera Jefe de Gabinete del GCBA en esos años, comunicó públicamente que el fallo sería apelado: "Nosotros vamos a apelar el fallo; nos parece muy a la ligera esto de convalidar a gente que toma un lugar hace unos años y ahora hay que darle la propiedad de la tierra". ${ }^{27}$ Asimismo, el Jefe de Gobierno Mauricio Macri planteó: "Hay definiciones de algunos jueces que son inentendibles. No podemos urbanizar así de fácil unas tierras que fueron tomadas de manera ilegal. Nosotros estamos muy firmes con ese tema porque si no con ese criterio mañana nos toman la Ciudad". ${ }^{28}$ Bajo el calificativo de "ocupantes" e "ilegales", estos relatos dan cuenta, una vez más, de las expulsiones simbólicas y morales (Carman, 2011) que recaen en estos habitantes, a la vez que recobra fuerza, en los predios lindantes al barrio, el proyecto urbanístico de viviendas y espacios de recreación marina a cargo de IRSA. ${ }^{29}$

A una semana de la sentencia de la jueza, el GCBA presentó, con el patrocinio de la Procuración General de la Ciudad de Buenos Aires, un recurso formal de apelación. ${ }^{30}$ La Sala II de la Cámara de Apelaciones en lo Contencioso Administrativo y Tributario de la Ciudad de Buenos Aires resolvió, en septiembre de 2014, hacer lugar al recurso y revocar la sentencia de primera instancia. ${ }^{31}$ Las argumentaciones de los magistrados en mayoría, en contraposición

\footnotetext{
27 "La Ciudad calificó de "disparate" el fallo que ordenó urbanizar otra villa". Diario Infobae. 24/03/11. (Disponible en: https://www.infobae.com/2011/03/24/571547-la-ciudad-califico-disparate-el-fallo-que-ordenourbanizar-otra-villa/).

28 "El Gobierno porteño apelará el fallo que le ordena urbanizar una villa de Costanera Sur". Diario Clarín. 24/03/2011. (Disponible en: https://www.clarin.com/capital federal/Gobierno-apelara-urbanizar-CostaneraSur_0_ryw_khETD7g.html).

${ }^{29}$ Este punto será ampliado a continuación.

${ }^{30}$ Exp.17699/0. “Apela-Expresa Agravios-Reserva el caso Federal y Cuestión Constitucional”. Fecha 30/03/2011. Procuración General de la Ciudad de Buenos Aires.

${ }^{31}$ Fallo revoque sentencia. Exp. $\mathrm{N}^{\circ} 17699 / 00$ : “Zarate Villalba, Juan Ramón y Otros C7 GCBA s/Amparo", Fuero Contencioso Administrativo y Tributario. 30/09/2014.
} 
al dictamen de la jueza de urbanizar Rodrigo Bueno, fueron diversas. ${ }^{32}$ En ellas se omitió el reconocimiento a la preexistencia de la villa respecto de la Reserva Ecológica sin considerar el proceso socio-histórico de la conformación de la población en el lugar. También alegaron la posibilidad que otorgó el GCBA a estos habitantes de trasladarse voluntariamente del predio mediante una cobertura habitacional, sin contemplar el carácter represivo y las exiguas posibilidades reales de salida que, lejos de resolver la situación de los habitantes, tendió a agravarla. Otro de los argumentos remitió a las facultades de los poderes. Los magistrados sostuvieron que por razones de carácter constitucional es el poder legislativo quien tiene la potestad para diseñar la urbanización de la ciudad de Buenos Aires, facultad que le excede al poder judicial. Sin embargo estos magistrados no contemplaron la existencia de la Ley 148, sancionada en 1998, que establece un tratamiento prioritario orientado a garantizar la urbanización de las villas de la ciudad, con responsabilidades concretas de parte del GCBA. ${ }^{33}$ En este sentido tampoco se reconoció la limitación y discrecionalidad del propio GCBA en promover el derecho a la vivienda y a la ciudad de estas poblaciones en un contexto de déficit y precariedad persistente. Quizá parte de ese "no" reconocimiento de los magistrados -a la Ley 148 y sobre el proceder deficiente del GCBA- tuviera una intencionalidad: la de no atribuir al poder judicial la facultad de exigir rendición de cuenta al ejecutivo local en el cumplimiento de estos derechos, considerando así el dictamen de la jueza un "exceso".

\section{Otros actores haciendo frente al revés}

Con los argumentos explicitados anteriormente ${ }^{34}$ el tribunal procedió a revocar la sentencia de la Jueza Liberatori, no obstante la Defensoría General de la Ciudad apeló ante la Cámara de Apelaciones en defensa de los habitantes. Así lo expresó el defensor general: "recurrimos la sentencia ante el Tribunal Superior de Justicia que va a tener la oportunidad de venir al barrio y darles a los vecinos el derecho a vivir dignamente en la Ciudad como cualquier otro.

\footnotetext{
${ }^{32}$ El fallo contó con el voto de tres magistrados, de los cuales dos de ellos coincidieron en dar lugar a la apelación del GCBA, mientras que la tercera letrada tuvo una postura disidente, en rechazo a los fundamentos de la apelación. Bajo estos resultados se procedió a revocar la sentencia de grado.

${ }^{33}$ Ver "Declaración por Fallo sobre urbanización Barrio Rodrigo Bueno" realizada por los investigadores y becarios del Área de Estudios Urbanos del Instituto de Investigaciones Gino Germani en rechazo al presente fallo. (Disponible en: https://www.facebook.com/notes/\%C3\%A1rea-de-estudios-urbanos-instituto-de-investigacionesgino-germani/por-favor-difundir-rechazo-del-fallo-que-revoca-la-urbanizaci\%C3\%B3n-del-barriorodri/866511333380027).

${ }^{34}$ Estos son algunos de los argumentos centrales presentes en el fallo.
} 
Somos todos iguales". ${ }^{35}$ Y agregó: "el fallo de cámara es una construcción artificiosa contraria a toda voluntad de urbanización, propio de una justicia divorciada de la realidad. Es un fallo muy negativo, no sólo para los vecinos sino también discordante con el avance de las soluciones habitacionales para estos barrios". 36

Por su parte, la ACIJ y el Centro de Estudios Legales y Sociales (CELS) presentaron un escrito al Tribunal Superior de Justicia solicitando ser tenidos en cuenta como amicus curiae (amigos del tribunal) en colaboración con la causa. ${ }^{37}$

Ambas organizaciones sostuvieron que los conocimientos y experiencias adquiridas en sus trayectorias como asociaciones civiles son de utilidad para dilucidar los derechos que están en juego y esclarecer cuestiones de suma importancia en la causa.

Como puede verse, en esta productividad del conflicto fueron diversos los actores que, dentro del plano judicial intervinieron y buscaron -a través de sus recursos, facultades y roles institucionales- incidir en la toma de decisión sobre los destinos de esta población mediados por procesos de judicialización.

\section{El poder legislativo también como arena de disputa}

En el año 2011 el GCBA llevó adelante dos acciones interrelacionadas que merecen su atención. Mientras en Rodrigo Bueno comenzó el proceso de intervención judicial para la elección formal de los delegados, el GCBA apeló el fallo de la Jueza Liberatori -en el cual dictaba sentencia a favor de la urbanización de la villa- al mismo tiempo que volvió a enviar a la Legislatura el proyecto de urbanización de IRSA "Solares Santa María”. Estas estrategias permiten ver la clave política de la apelación del fallo donde la cuestión de fondo es cómo se distribuyen las cargas y beneficios de la urbanización formal. De este modo, el conflicto preexistente acerca de quiénes pueden hacer uso del suelo urbano, -y que había comenzado a desplegarse en el ámbito judicial- también pasó a problematizarse en la arena legislativa.

Eduardo Elsztain, presidente de IRSA se presentó en la Legislatura de la Ciudad con sus directivos y técnicos ${ }^{38}$ para informar las características del emprendimiento y brindar

\footnotetext{
${ }^{35}$ El Tribunal Superior de Justicia decidirá la urbanización de la Villa "Rodrigo Bueno". Tiempo Judicial. (Disponible en internet: http://www.tiempojudicial.com/web/el-tribunal-superior-de-justicia-decidira-laurbanizacion-de-la-villa-rodrigo-bueno/10328).

36 Ídem.

${ }^{37}$ En el documento exponen la génesis del amicus curiae y su aceptación a nivel Internacional y Nacional (Art. 33 de la Constitución Nacional) partiendo de la idea de que un Estado de Derecho trae aparejada la necesidad de permitir a diferentes organizaciones civiles presentarse espontáneamente en todos los juicios que conlleven el tratamiento de la vigencia de derechos humanos (Documento de solicitud en calidad de amicus curiae ante el Tribunal Superior de Justicia. ACIJ y CELS, 2015. Disponible en: https://www.cels.org.ar/common/documentos/Amicus\%20Rodrigo\%20Bueno.pdf).

${ }^{38}$ Se hicieron presentes el vicepresidente de IRSA (Sr. Zang), asesora en Planeamiento Urbano (Sra. Varela), responsable de la Gerencia de Tierras (Sr. Villaveirán), responsable de la Gerencia de Relaciones Institucionales del grupo, (Sra. Lascano), responsable a cargo de la Gerencia de Operaciones y Desarrollo del Grupo (Sr. Mandachaín), proyectista del Diseño Urbano (Sr. Baudizzone) e ingenieros que conforman el equipo técnico.
} 
respuestas a las dudas e inquietudes de los diputados porteños. Esta reunión tuvo lugar el 1 de noviembre de 2011 y contó con la presencia de diversos actores: diputados ${ }^{39}$ y asesores legislativos, directivos de IRSA, vecinos de Rodrigo Bueno, representantes de organizaciones en defensa del medio ambiente y de la Reserva Ecológica, vecinos de diferentes barrios de la Ciudad, investigadores, periodistas, y público diverso. La primera palabra la tuvo el presidente de la empresa quien hizo un recorrido sobre la historia de la compañía y los emprendimientos urbanos llevados adelante. En torno al proyecto Solares Santa María enfatizó que el mismo no es un barrio cerrado sino accesible a los ciudadanos. En su presentación también recalcó la importancia de este emprendimiento, en tanto, no sólo se emplaza en los terrenos más estratégicos de la ciudad, ${ }^{40}$ tendientes a contribuir al desarrollo y puesta en valor de la zona sur, cuya ubicación privilegiada en el corredor costero resulta un nexo entre el norte y sur de la ciudad, sino también enfatizó la generación de nuevos puestos de trabajo y una mayor recaudación de impuestos para el GCBA.

Los diputados no tardaron en hacer sus intervenciones. Entre las observaciones, Adrián Camps $^{41}$ hizo referencia a la villa Rodrigo Bueno y a la situación de sus habitantes quienes al momento no tenían agua corriente, y enfatizó -en alusión al artículo 18 de la Constitución de la Ciudad ${ }^{42}$ - que esa situación debe ser contemplada antes de realizar un desarrollo de gran magnitud para evitar acrecentar las desigualdades en la Ciudad. El presidente de IRSA aclaró que los predios donde se encuentra Rodrigo Bueno no son competencia de la empresa y que el futuro de esos espacios depende de la Legislatura.

El emprendimiento Solares Santa María siguió en discusión en las comisiones de la Legislatura de la Ciudad a lo largo del 2012, incluso bajo sesiones extraordinarias, sin embargo a pesar de la insistencia del ejecutivo de la Ciudad por su tratamiento, el mismo no fue aprobado. Bajo el lema: "No a la entrega de la Ciudad a las grandes corporaciones" vecinos de Rodrigo Bueno, referentes de otras villas y militantes de organizaciones territoriales y de derechos humanos marcharon y reclamaron frente a la Legislatura. Allí manifestaron su rechazo a la aprobación de un paquete de leyes con el fin de impulsar el desarrollo de emprendimientos privados, entre los cuales se encontraba Solares Santa María. Quienes se manifestaron, expusieron con banderas y carteles algunas propuestas: urbanización y

\footnotetext{
${ }^{39}$ Se encontraron presentes las diputadas Silvina Pedreira, Rocío Sánchez Andía y María José Lubertino, y los diputados Sergio Abrevaya, Adrián Camps, Álvaro González, Cristian Ritondo y Bruno Screnci Silva.

${ }^{40}$ En su presentación Elsztain señaló que los predios de la ex Ciudad Deportiva de Boca Juniors es el activo más importante que la compañía posee, por su localización pero también porque no existe en la Ciudad de Buenos Aires un terreno de 70 hectáreas como éste.

${ }^{41}$ Legislador porteño proveniente del Movimiento Proyecto Sur, integrante del Partido Socialista Autentico (PSA).

${ }^{42}$ Art. 18. La Ciudad promueve el desarrollo humano y económico equilibrado, que evite y compense las desigualdades zonales dentro de su territorio.
} 
radicación definitiva en el lugar de las villas y barrios precarios, suspensión de desalojos, regulación del mercado de alquileres. Cabe señalar que a pesar de no haberse aprobado aún el proyecto IRSA, las disputas y tensiones en torno a los usos de estos espacios en la Costanera Sur se mantienen presentes y se evidencian tanto en el plano judicial como legislativo.

Otro efecto de la judicialización que venimos anticipando es que la sentencia fue reorganizadora del conflicto. A partir de ella, el conflicto no sólo no fue igual sino que se reconfiguró en otras arenas, como el ámbito legislativo, sumando nuevos actores a la contienda (diputados, desarrolladores urbanos, vecinos).

En el año 2014 referentes de Rodrigo Bueno junto con la Defensoría del Pueblo y el Ministerio de la Defensa General de la Ciudad de Buenos Aires presentaron un nuevo proyecto de ley para promover la integración urbana de la villa. La Legislatura se convirtió así en un escenario "formal" de disputa y contrapeso de intereses divergentes. Como venimos señalando los actores con incidencia territorial hicieron uso de este espacio en busca de una "resolución" de los conflictos buscando enfatizar y dar legitimidad al posicionamiento que cada uno tuvo. ${ }^{43}$ Una lucha simbólica mediada por un cuerpo de profesionales de la representación que funcionaron como portavoces de cada grupo de agentes (Bourdieu, 2001). El ámbito judicial y legislativo funcionó aquí como un "campo" -de fuerzas- cuyos agentes buscaron imponer, a través de argumentaciones, sus construcciones y representaciones del mundo para luego actuar sobre él, en este caso sobre los usos de la ciudad de un sector localizado en una villa de Buenos Aires.

\section{Reflexiones acerca de la judicialización}

En este trabajo me propuse reconstruir el proceso de judicialización de la villa Rodrigo Bueno recuperando los aportes de Merlinsky (2015), Melé (2003), Azuela y Cosacov (2013), en torno a dos aspectos: por un lado, acerca de los efectos sociales de esta modalidad de intervención

\footnotetext{
${ }^{43}$ Mientras tanto en el barrio Rodrigo Bueno se seguían sucediendo cosas a causa de la informalidad persistente. La muerte de Guido, un niño de 13 años, que cayó a un pozo ciego en marzo de 2015 reforzó la demanda de los habitantes de que el GCBA interviniese en pos de mejorar las condiciones habitacionales y de vida. En ese contexto un referente del barrio presentó ante la Comisión Interamericana de Derechos Humanos (CIDH) en Washington, EE.UU., la situación de Rodrigo Bueno como caso expresivo de la vulneración de los derechos económicos, sociales y culturales en asentamientos precarios de América Latina. Ese testimonio, ampliamente cubierto por los medios locales, se dio en el marco de una presentación conjunta de varios organismos de la región, incluyendo a la Defensoría General Porteña, el CELS y la ACIJ por la Argentina. Aunque no tiene efectos prácticos sobre el estatuto jurídico del barrio, estas acciones forman parte de una estrategia de incidencia que acompañó la judicialización del caso, a cargo del Tribunal Superior de Justicia, máxima instancia de la ciudad (Vitale \& Rodríguez, 2016).
} 
y por otro, sobre la productividad social de la judicialización; es decir, cómo se construye la realidad social en un tema “judicializable” y el rol que desempeñan los actores que intervienen en este campo de acción.

Rodrigo Bueno se instaló como un tema a resolverse en el campo judicial a partir de la elaboración del amparo impulsado por los propios habitantes junto a la APDH frente al proceso de expulsión que el Gobierno de la Ciudad inició en el 2005.

En este marco, la expertise legal y del derecho (Merlinsky, 2015) de las abogadas de la APDH jugaron un papel importante en la elaboración del expediente. En colaboración con los vecinos, quienes acercaron documentos y testimonios, las letradas construyeron un argumento en defensa de la permanencia de los habitantes en el lugar. Centralmente enfatizaron el carácter irregular y violento que asumió la expulsión del GCBA sin brindar alternativas habitacionales concretas que mejoren la situación de las familias, así como la historia y consolidación del barrio a lo largo de los años resaltando la importancia de su inclusión a procesos de radicación.

Los aportes de Azuela y Cosacov (2013) fueron relevantes para pensar el peso que aquí asumió la argumentación y la construcción de sentidos de los actores intervinientes sobre lo que “debe” hacerse en el marco de la ley. En la sentencia del 2011, la jueza Liberatori reconoció el derecho de los habitantes de Rodrigo Bueno a permanecer en el lugar y exigió al GCBA a efectuar acciones concretas para la integración urbanística y social del barrio, sobre la base de un fundamento normativo. Sin embargo, el corpus jurídico no fue de lo único que se valió para la construcción del argumento. La jueza también tuvo en consideración los trabajos e informes realizados por investigadoras del CONICET, profesionales y técnicos que tomaron en cuenta aspectos referidos a lo habitacional, ambiental y social.

Uno de los efectos de la judicialización del conflicto en Rodrigo Bueno fue precisamente la participación de nuevos actores (en este caso académicos y profesionales) con injerencia en la justificación y construcción de registros de legitimidad (Merlinsky, 2015). El perfil de la magistrada y la apertura con que abordó el tema constituyó un factor de peso en la construcción del argumento y en la resolución judicial al respecto.

Asimismo, otro de los efectos de la judicialización fue que el derecho reorganizó el conflicto. Si al momento del desalojo los habitantes de Rodrigo Bueno eran "usurpadores" y "ocupantes ilegales", con la sentencia judicial pasaron a ser "sujetos de derecho". Esto generó contrapuntos, pues el ejecutivo del GCBA apeló al fallo de la jueza y emergieron nuevos actores en escena a favor y en contra de esta reacción adversa (magistrados, Defensoría General de la Ciudad, organismos de derechos humanos). 
Como desarrollamos al principio, las disputas traducidas en argumentos y fallos cristalizaron un conflicto social urbano, sobre la legitimidad de quienes pueden hacer uso del área donde se encuentra la villa Rodrigo Bueno. Estas disputas por el control del territorio también hicieron eco en la arena legislativa. Pues mientras el GCBA apelaba el fallo de la jueza Liberatori, el bloque del PRO presentó en la Legislatura el proyecto de urbanización de Solares Santa María a cargo de IRSA. Por su parte, tiempo después los habitantes de Rodrigo Bueno presentaron un nuevo proyecto de ley para promover la integración urbana de la villa, logrando la normativa de reurbanización en 2017.

En este sentido, podemos ver que el campo de la judicialización no sólo operó como instrumento, según la expectativa de los agentes de dar resolución a un problema, sino que fue performativo de nuevas dinámicas y estrategias de acción. Asimismo, la disputa por los sentidos en el campo judicial acerca de quiénes pueden hacer uso del espacio urbano y los beneficios de la urbanización nos permitió comprender que los argumentos no son unívocos ni homogéneos, y que quienes sostenían una postura podían modificarla a través del tiempo, mediante la reelaboración de estrategias y posiciones diversas (Merlinsky, 2015).

Hoy la Rodrigo Bueno se encuentra atravesada por un proceso de integración social y urbana a cargo de Horacio Rodríguez Larreta, quien tiempo atrás argumentó la necesidad de desalojar el predio en oposición al dictamen de la jueza, y cuya intervención se sustenta en la ley de reurbanización del barrio lograda por la demanda de las propias familias.

Una reurbanización que no podemos negar se desplegó en el marco de importantes inversiones inmobiliarias en la zona, pero que también permitió vislumbrar los efectos sociales del proceso de judicialización impulsado por los habitantes de Rodrigo Bueno en reclamo, frente al desalojo de 2005, a vivir y permanecer en ese lugar. Quedará abierta la pregunta si la urbanización actual es la expulsión silenciada por la vía del mercado y si esto abrirá nuevos conflictos por el uso y la apropiación de ese suelo en un área central de la Ciudad.

\section{Bibliografía}

Abramovich, V. (2009). El rol de la justicia en la articulación de políticas y derechos sociales. En V. Abramovich, \& L. Pautassi, La revisión judicial de las políticas sociales. Estudio de casos. Buenos Aires: Del Puerto.

Alimonda, H. (2013). Prólogo. En G. Merlisnky (Comp.) Cartografías del Conflicto Ambiental en Argentina. Buenos Aires: Ciccus.

Arqueros Mejica, S., Calderón, C., Jauri, N., Ramos, J., Vitale, P., \& Yacovino, P. (2013). Política y Derecho en la judicialización de demandas colectivas de las villas de la Ciudad. 
En L. Bercovich, \& G. Maurino, Los derechos sociales en la gran Buenos Aires. Algunas aproximaciones desde la teoría, las instituciones y la acción (pp. 155-172). Buenos Aires: EUDEBA.

Azuela, A. (2006). Visionarios y pragmáticos. Aproximación sociológica al derecho ambiental. México: Fonatamara.

Azuela, A., \& Cosacov, N. (2013). Transformaciones urbanas y reivindicaciones ambientales. En torno a la productividad social del conflicto por la construcción de edificios en la Ciudad de Buenos Aires. Revista EURE (Santiago), XXIX(18), 149-172.

Azuela A. (2014) Introducción. Los juristas y las ciencias sociales frente al activismo judicial y los conflictos urbano-ambientales en América Latina. En A. Azuela y M. Á. Cancino (Coords.) Jueces y conflictos urbanos en América Latina (pp. 7-33). México: PAOTIRGLUS.

Bourdieu, P. (2001). El campo político. Bolivia: Plural editores.

Carman, M. (2011). Las trampas de la naturaleza. Medio ambiente y segregación en Buenos Aires. Buenos Aires: Fondo de la Cultura/CLACSO.

Cuenya, B. (2011). Grandes proyectos y sus impactos en la centralidad urbana. (U. O. Catalunya, Ed.) Carajillo de la ciudad, Revista Digital del Programa Gestión de la Ciudad(3).

Delamata, G., Sehtman, A., \& Ricciardi, M. V. (2014). Más allá de los estrados... activismo judicial y repertorios de acción villera en la Ciudad de Buenos Aires. En L. Pautassi, comp.- Marginaciones sociales en el AMBA: acceso a la justicia, capacidades estatales y movilización legal. Buenos Aires: Biblos.

Delamata, G. (2016). Una década de activismo judicial en las villas de Buenos Aires. Revista Direito \& Praxis, 07(14), 567-587.

Domingo, P. (2009). Ciudadanía, derechos y justicia en América Latina. Revista CIDOB d Afer Internacionals(85-86), 33-52.

López Oliva , M. (2009). El litigio individual en derechos sociales. Una aproximación al estado actual en la Ciudad de Buenos Aires. En V. Abramovich \& L. Pautassi, La revisión judicial de las políticas sociales. Estudios de casos. Buenos Aires: Edit. Del Puerto.

Maurino, G. \& Nino, E. (2009). Judicialización de políticas públicas de contenido social. Un examen a partir de casos tramitados en la Ciudad de Buenos Aires. En V. Abramovich, \& L. Pautassi, La revisión judicial de las políticas sociales. Estudios de casos. Buenos Aires: Edit. Del Puerto. 
Melé P. (2003) Introduction: Conflits, territoires et action publique. En P. Melé, C. Larrue \& M. Rosemberg (Coords.), Conflits et territories, (pp. 13-32). Tours: Presses Universitaires Franois-Rabelais.

Merlinsky, G. (2015). Los conflictos ambientales y el debate público sobre el desarrollo en Argentina. Ciencia e Investigación. Tomo 65(3).

Pírez, P. (1994). Buenos Aires Metropolitana. Política y gestión de la ciudad. Buenos Aires: Centro Editor de América Latina.

Ramos, J., \& Vitale, P. (2011). De luchas y leyes: la experiencia de la Mesa por la urbanización y radicación de la Villa 31 -31 bis y su relación con el Estado. En P. Urquieta, Ciudades en Transformación. Disputas por el espacio, apropiación de la ciudad y prácticas de ciudadanía (pp. 295-314). La Paz: Plural.

Rodríguez, M. C., \& Di Virgilio, M. M. (2012). Coordenadas para el análisis de las políticas urbanas: un enfoque territorial. En M. Rodríguez, \& M. M. Di Virgilio, Caleidoscopio De Las Políticas Territoriales. Un rompecabezas para armar (pp. 17-46). Buenos Aires: Prometeo Libros.

Rodríguez, M. F. (2009). La política de erradicación en el Asentamiento Rodrigo Bueno Costanera Sur. Un análisis desde la dimensión espacial. Revista Digital MUNDO URBANO (34). Universidad Nacional de Quilmes. ISSN: 1515-8373

Rodríguez, M. F. (2012) Los desalojos en los Nuevos Asentamientos urbanos (NAU) de la ciudad de Buenos Aires. Un estudio de caso del Asentamiento Costanera Sur Rodrigo Bueno. Publicación Tesis de Maestría - 1a ed. Buenos Aires: Centro Cultural de la Cooperación. ISBN 978-987-33-1710-1. Disponible en: https://www.centrocultural.coop/publicaciones/los-desalojos-en-los-nuevosasentamientos-urbanos-nau-de-la-ciudad-de-buenos-aires-un

Rodríguez, M. F. (2015). El papel de la localización en las disputas por el espacio urbano: accionar estatal y prácticas organizativas en villas tipificadas "como no regularizables" de la Ciudad de Buenos Aires, 2001-2015. Tesis doctoral. Facultad de Ciencias Sociales. Universidad de Buenos Aires.

Rodríguez, M. F. (2019). “Eviction” (entrada sobre desalojos) en Encyclopedia of Urban and Regional Studies. [EURS 0452]. Editor: Anthony M. Orum. ISBN: 978-111-8568-44-6.

Smulovitz, C. (2008). Organizaciones que invocan derechos. Sociedad civil y representación en Argentina. Revista Postdata(13), Buenos Aires.

Vitale P. y Rodríguez M. F. (2016). Dinámicas urbanas y hábitat popular. Vaivenes de una política fallida de integración social y urbanística en la Comuna 1. En M. C. Rodríguez y 
M. M. Di Virgilio (Comp.) Territorio, políticas habitacionales y transformaciones urbanas (pp. 207-238). Buenos Aires: Espacio Editorial.

von Lucken M. \& Rodríguez M. F. (2011). Los desalojos como política de Estado. Un estudio de caso villa La Maternidad en la ciudad de Córdoba y el asentamiento Costanera Sur Rodrigo Bueno en la ciudad de Buenos Aires. En H. Herzer (Comp.) La Cuestión Urbana Interrogada. Transformaciones urbanas, ambientales y políticas públicas en Argentina (pp. 207-236). Buenos Aires: Ediciones El café de las ciudades. ISBN: 978-987-25706-13.

\section{Expedientes y documentos jurídicos}

Decreto 1247/05 publicado en el B.O. № 2265 el 2005-08-31. Disponible en: https://boletinoficial.buenosaires.gob.ar/normativaba/norma/75664

Resolución $\mathrm{N}^{\circ}$ 0720/09: Cementerio de autos ubicado entre la Reserva Ecológica y la villa

Rodrigo Bueno, Resolución Nº720/09 (Defensoría del Pueblo de la Ciudad de Buenos Aires 13 de Marzo de 2009).

Exp. N¹7699/00: Apela-Expresa Agravios-Reserva el caso Federal y Cuestión Constitucional, Exp. n¹7699/00 (Procuración General de la Ciudad de Buenos Aires 30 de Marzo de 2011).

Exp. N¹7699/00: "Zarate Villalba, Juan Ramón y Otros C7 GCBA s/Amparo", Exp. N¹7699/00 (Fuero Contencioso Administrativo y Tributario, Poder Judicial de la Ciudad de Buenos Aires 30 de Septiembre de 2014).

ACIJ \& CELS (2015). Documento de solicitud en calidad de amicus curiae ante el Tribunal Superior de Justicia. Disponible en:

https://www.cels.org.ar/common/documentos/Amicus\%20Rodrigo\%20Bueno.pdf 